\title{
Toward the origin of amniotes: Diadectomorph and synapsid footprints from the early Late Carboniferous of Germany
}

Sebastian Voigt and Michael Ganzelewski

Acta Palaeontologica Polonica 55 (1), 2010: 57-72 doi: http://dx.doi.org/10.4202/app.2009.0021

Ichnotaxonomic revision of two extended sequences of large tetrapod footprints from the Westphalian A Bochum Formation of western Germany suggests assignment of the specimens to the well-known Permo-Carboniferous ichnogenera Ichniotherium and Dimetropus. Trackway parameters and imprint morphology strongly support basal diadectomorphs and "pelycosaurian"-grade synapsid reptiles, respectively, as the most likely trackmakers. The ichnofossils thereby extend the first appearance of these two important groups of basal tetrapods by about 5-10 million years, to the early Late Carboniferous, which is in accordance with the minimum age for the evolutionary origin of the clades following widely accepted phylogenetic analyses. These trackways provide not only direct evidence bearing on activity and behaviour of large terrestrial tetrapods close to the origin of amniotes, but also serve as a valuable benchmark for the assessment of controversially interpreted vertebrate tracks from other localities of similar age.

Key words: Ichniotherium, Dimetropus, Cotylosauria, tetrapod tracks, Westphalian, Germany.

Sebastian Voigt [‥voigt@geo.tu-freiberg.de], Geologisches

Institut, Technische Universität Bergakademie Freiberg, Bernhard-von-Cotta-Straße 2, 09599 Freiberg, Germany; Michael Ganzelewski [michael.ganzelewski@bergbaumuseum.de], Montanhistorisches Dokumentationszentrum, Deutsches Bergbau-Museum, Am Bergbaumuseum 28, 44791 Bochum, Germany.

This is an open-access article distributed under the terms of the Creative Commons Attribution License (for details please see creativecommons.org), which permits unrestricted use, distribution, and reproduction in any medium, provided the original author and source are credited. 
FoF Full text $(1,209.1 \mathrm{kB})$ 